\title{
IMPLEMENTATION OF LONGITUDINAL WELDING STRESSES INTO STRUCTURAL CALCULATION OF STEEL STRUCTURES
}

\author{
Hartmut PASTERNAK ${ }^{\mathrm{a}}$, Gabriel KUBIENIEC ${ }^{\mathrm{b}}$ \\ Brandenburg University of Technology, Chair for Design of Steel and Timber Structures, Cottbus, Germany
}

Received 16 Jan 2014; accepted 15 Sep 2014

\begin{abstract}
During welding of typical steel cross sections, like T or I- Profiles e.g., residual stress occurs and need to be considered during the design process. With knowledge of the stress state after welding, farther calculation with different models are carried out. The systematic study will show three steps of the Okerblom's model to consider in the evaluation process of the welding stresses. The results of the numerical simulation and experimental models are show and compared. With that, the difference between the buckling curve from EN 1993-1-1 (2006) and the study are shown for steel S235 and S460. Especially for the high strength steels, the nowadays design conditions are very conservative and further investigation is needed and recommended.
\end{abstract}

Keywords: longitudinal welding stresses, compression steel members, GMNIA, geometrical imperfection, European buckling curves, Heat Affected Zone (HAZ).

\section{Introduction}

This paper focuses on the introduction of longitudinal welding stresses into structural calculations of compression steel members. There were presented the nowadays used methods of including these stresses into calculation, i.e.: (1) $\chi$ - procedure (European buckling curves); (2) equivalent geometrical imperfection procedure; and (3) yield zone theory (GMNIA). In case of the third method, which requires a direct implementation of welding stresses, a model was shown based on experiments and analytical models were designed to predict the representative longitudinal welding stresses. As an example of analytical model, shrinkage force modelled by Okerblom (1958) was briefly described. This model was experimentally and numerically validated and compared with existing experimental models. The tests which were carried out in Pasternak et al. (2011) confirmed the assumptions and good adequacy of results delivered by Okerblom's model.

\section{State of art}

\subsection{Description of residual stresses}

During welding three types of imperfections may arise i.e. structural, geometrical and assembly. The knowledge of the welding process and the ease of identification of welding deformations in welded members allow to reduce the geometrical imperfections to a minimum level. The reduction of structural imperfections i.e. residual stresses is usually very difficult or even not possible and only by adequate design (structural and technological) of such elements, the negative influence of structural imperfections can be minimized. Due to very high energy introduction during welding, the area around the weld is strongly heated and tries to extend, but surrounding parts of profile which are less heated prevent this process. As a consequence of this arise the residual tension stresses close to the weld reach the yield strength of the material and cause the plastic shortening of fibres of profile. In the less heated areas of the profile, around the weld, balancing compression stresses occur (Schulz 1968). The typical distributions of welding residual stresses and the accompanying geometrical imperfections were presented in Figure 1. Huge heat introduction into welded pieces arises in the area of base material, which its microstructure and properties altered by welding. This area is so called Heat Affected Zone (HAZ). The extent and magnitude property change (HAZ) depends primarily on the base material, the weld filler metal, the amount and concentration of heat input by the welding process (welding technique) (see Fig. 2).

The calculation of the temperature field exiting during the welding process (see Fig. 2) is the most important information regarding to description of HAZ. The temperature field is influenced by welding parameters, weld form, geometry of welded member and physical material properties. The introduced heat is different for every welding technique and influences not only the temperature field but also the breadth of HAZ and is a source of residual welding stresses and deformations.

Corresponding author: Hartmut Pasternak

E-mail: h.pasternak@tu-cottbus.de 

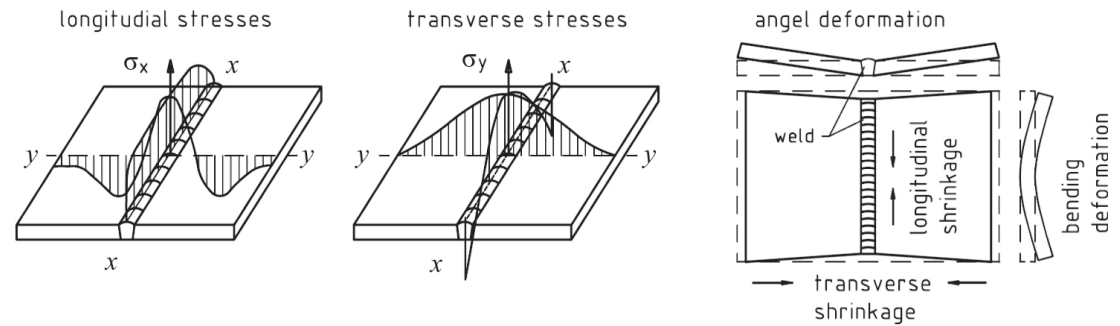

Fig. 1. Structural and geometrical imperfections after welding (Radaj 1998)
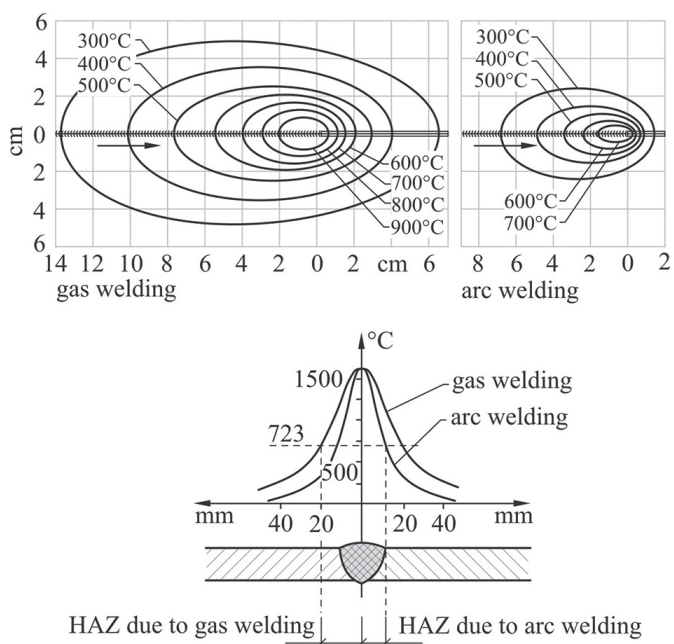

Fig. 2. Temperature distribution during the welding (Pasquale 2001)

\section{Residual welding stresses in structural calculations}

The structural imperfections should be taken into consideration during the structural calculations of stability sensible members. To determine the capacity of such members the following calculation methods can be used: (1) $\chi$ - procedure (European buckling curves); (2) equivalent geometrical imperfection procedure; and (3) yield zone theory (GMNIA).

\section{1. $\chi$ - procedure (European buckling curves)}

In this procedure all internal forces are determined according to elasticity theory (1st order theory). In the reality, the influence of deformation on the value of internal forces (2nd order theory) as well as other effects (geometrical and structural imperfections, extension of yield zone) are covered by reduction of factor $\chi$ depended on the imperfection factor $\alpha$ (in case of welded structures $0.34,0.49$ or 0.76 ) and distinguishes the buckling curves $\mathrm{b}, \mathrm{c}$ or $\mathrm{d}$. This procedure has one significant disadvantage i.e. the user of this method does not get any information about arising internal forces. The whole calculation is based on the buckling curves which are depended on the shape and dimensions of cross-section, manufacturing process (welding, rolling) and the yield strength of material. The diversification of buckling curves is mainly caused by the residual stresses which depend on above mentioned parameters and have again a big influence on the capacity of structural members (Wolf 2006).

\subsection{Equivalent geometrical imperfection procedure}

In EN 1993-1-5 (2006), Annex C in point C.5 (2) can be found: unless a more refined analysis of the geometric and the structural imperfections is carried out, equivalent geometric imperfections may be used. This procedure allows calculating the internal forces according to 2 nd order Theory with use of geometrical imperfections (see Fig. 5). The equivalent geometrical imperfection should be covered not only by the geometrical but also by structural (welding stresses) imperfections. With use of this method the user would be able to take into consideration many important factors such as: direct influence of geometrical imperfections, no limitations depending on static systems and more realistic behaviour of the structure. This procedure has following significant disadvantages which reduce the area of its application.

The available analytical solutions are limited to the simplest structural systems and in case of hand calculation the iterative procedure is not suitable. The requested values of amplitude of imperfections $e_{0}$ is depended on the method of calculation of capacity of element (see Fig. 3) which can be carried out as elastic or plastic analysis and the user has to choose between two possibilities. In case of elastic analysis, it is suggested that the calculations relate to elastic capacity of the member, however, in reality, it appears very often in plastic zones a)

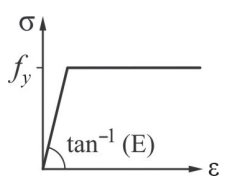

b)

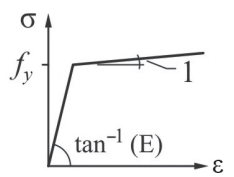

c)

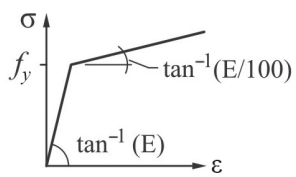

Fig. 3. Typical models of material behaviour (EN 1993-1-5 2006)

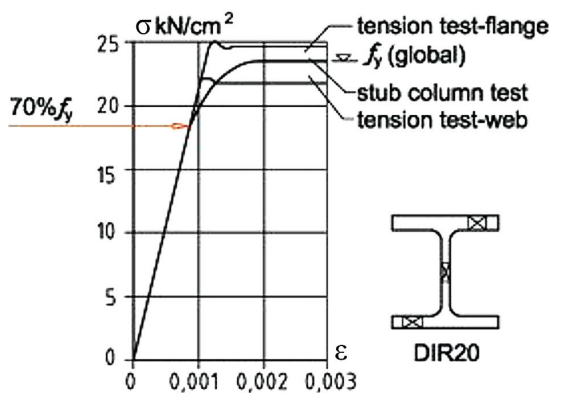

Fig. 4. Influence of residual stresses on the material behaviour (Schulz 1968) 
(Wolf 2006). Moreover this method is strictly connected with typical models of material (see Fig. 3) which suggest that the material behaves linear up to yield strength, while in reality the $\sigma-\varepsilon$ curve is significantly influenced by residual stresses (see Fig. 5).

\subsection{Yield zone theory (GMNIA)}

For the determination of structural elements capacity, the yield zone theory is the most accurate method. This method is based on the Geometrically and Materially Nonlinear Imperfections Analysis (GMNIA). The geometrical nonlinearity is considered by the initial geometrical imperfection which can be based on the shape of the critical buckling modes with amplitudes equal to $80 \%$ of the geometric fabrication tolerances described in EN 1090-2:2008 (2008). The material nonlinearity refers to adequate description of the elastic-plastic model behaviour of the steel material i.e. $\sigma-\varepsilon$ relationship. This relationship is significantly influenced by the residual stresses (see Fig. 4) which may be represented by a stress pattern from fabrication process with amplitudes equivalent to the mean (expected) values (EN 1993-1-5 2006). When the yield zone in the member appears (after exceeding the elastic strain), the stiffness of the member is changed. During the extension of the yield zone the calculations are carried out with the decreased value of elastic modulus $E$. This reduction is taken into consideration at the every increment of load and influences not only the deformability of model but also the increase of internal forces especially in presence of normal load. In this way the user receives the most adequate response of the structure. Here, the most important parameter is the lowest value of the plastic stresses. This value depends significantly on the residual stresses which influence the moment of the appearance of the first plastification in the member. The zones with the highest residual stresses reach first the maximum value of elastic stresses and in these zones the yield starts to develop. The question which arises here is, how the residual stresses are distributed in the cross-section and which parts of the element are predominantly subjected to forming of the yield zones. An answer to this question can be found in literatures only for typical I cross-sections (ECCS 1983; Johansson et al. 2007; Petersen 1993) (see Fig. 6).

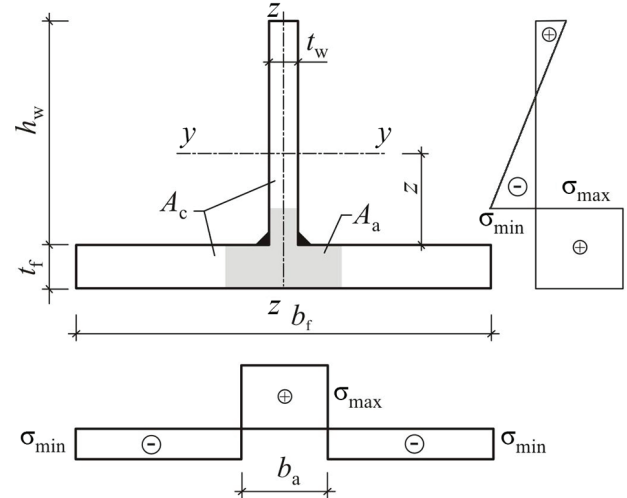

Fig. 5. Longitudinal welding stresses

\section{Basic parameters having influence on residual stresses}

The longitudinal welding stresses are stresses that remain after the removing the original cause i.e. which is the heat gradient in case of welding. The residual stresses can be divided in: type I stresses, i.e. stresses that act in the whole structural member or its part, type II stresses, i.e. stresses that act in the area of several grains and type III stresses, i.e. stresses that act in the area of several atoms (Radaj 1998). In design of welded structural members (beams and columns) the most interesting are the type I stresses. These stresses can be divided into tension stresses existing directly in the area of HAZ and compression stresses appearing outside this zone (see Fig. 5). All these stresses build a self-equilibrated system. Due to existence of those stresses in the cross-section, two different physical problems should be defined: the influence of tension stresses $\sigma_{\max }$ on the initiation of brittle cracking and the influence of compression stresses $\sigma_{\min }$ on the stability of compressed members (Rykaluk 1981). This paper deals with the second problem. There are several basic parameters which influence the distribution and welding stresses values. The first one is the yield stress of the base material. In case of structural steels, the welding tension stresses reach the magnitude of the yield strength. The breadth of HAZ is strongly depended on this parameter. The lower the yield strength is the bigger HAZ breadth gets (Lee, Chang 2007).
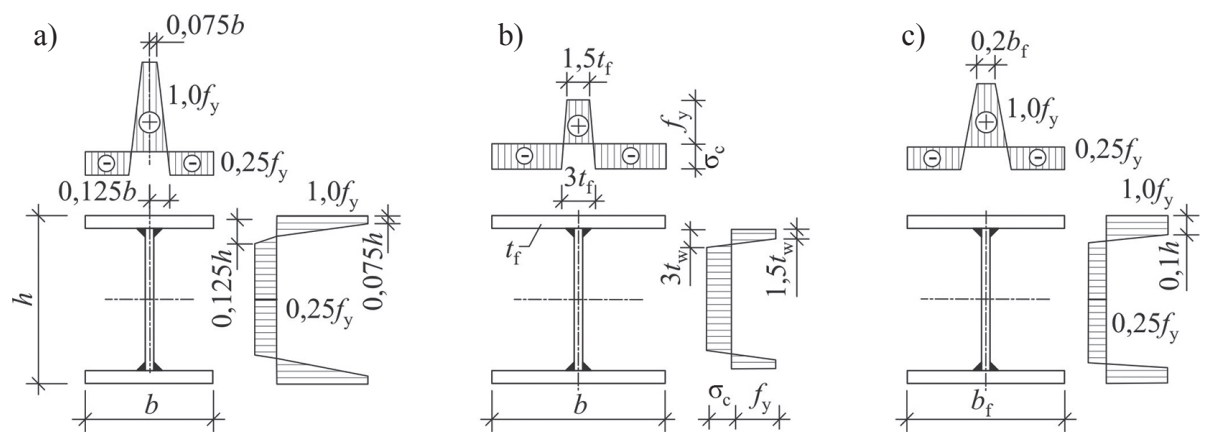

Fig. 6. Welding stress distribution according to: a) ECCS (1983); b) Johansson et al. (2007); c) Petersen (1993) 
Another situation is in case of high strength steels. The welding simulation carried out for I-cross sections made from steel Nionicral $70\left(f_{y}=810 \mathrm{~N} / \mathrm{mm}^{2}\right)(\mathrm{Beg}$, Hladnik 1994) showed that the welding tension stresses reach only the $50 \%$ of the yield strength of base material. The second parameter is the welding technique. By gas welding the size of zone of material affected by heat introduction is quite bigger than these caused by modern welding technologies (see Fig. 2). The breadth of HAZ has dominant influence of capacity of welded structures, which will be later presented. The third parameter is weld's thickness. The bigger the thickness of weld is, the bigger the breadth of HAZ gets and the compression residual stresses increase their magnitudes. This has special meaning during the welding of very thick plates requesting multi pass welding. In case of ideal welding parameters there are some proposals of equations used to write the linear warm energy in terms of weld thickness (Radaj 1998; Rykaluk 1981). The fourth parameter is shape of welded cross-section. The closed cross-sections (boxes) have bigger resistance to welding deformations in comparison with open cross-sections $(\mathrm{I}, \mathrm{T})$ and as a result show bigger residual stresses than the open crosssections (Rykaluk 1981).

This paper focuses on the precise description of longitudinal welding stresses and the way of taking these stresses into consideration during the structural design of welded elements.

\section{Models of residual stress distributions}

\subsection{Models based on experiments}

To answer the question how the residual stresses are distributed over the cross-section and which parts of the member are predominantly subjected to form the yield zones many researchers carried out experimental investigations. In Figure 6 there were presented longitudinal residual stress distributions determined during measurement carried out on real structural welded members. The values of residual stresses are formulated in the dependence of the yield strength what is not true in every case, especially in the case of high strength steels (Beg, Hladnik 1994). In case of models (a) and (c) the breadth of the HAZ is described as independent on the plate thickness, what is inconsistent with the reality. The arbitrary assumed distributions of compression residual stresses cannot be sufficiently explained and justified. These distributions are truthful only for the examined structural members and cannot be without doubts extended for other similar cross-sections. The lack of influence of welding parameters and stiffness of cross-section on the mentioned distributions makes these models inaccurate. The above mentioned disadvantages do not allow use of these models without doubts during the calculations of similar cross-sections and require the better description which can be delivered either by welding simulations or by analytical models.

\subsection{Analytical model}

The above described methods of determination of residual stresses are very extensive techniques. To avoid this problem there are proposed analytical shrinkage force model, created by Okerblom in the 50 s of the last century (Okerblom 1958). This model is not much known in the western hemisphere. It bases on two assumptions i.e. the 3-Bar model (see Fig. 7a) and the simplified yield strength - temperature relationship (see Fig. 7b). The 3-Bar model consists of 3 bars connected by two transverse yokes. The cross-section of the inner bar is equal to sum of cross-sections of both exterior crosssections. The inner bar is heated in some small area, like during welding. It extents constantly to the temperature of $600{ }^{\circ} \mathrm{C}$. Above this temperature there will be no further extensions of this element that is caused by rapid decrease of yield strength (see Fig. 7b). The surrounding not-heated bars limit the extension of the heated bar. As a consequence tension stresses appear in the inner bar and compression stresses in the exterior bars. The relationship between temperatures to which the inner element is heated and appearing in it appropriate values of residual stresses, show the slanting lines on the Figure $7 \mathrm{~b}$, for example A1-O. To the temperature $300{ }^{\circ} \mathrm{C}$, the residual stresses in the heated bar increase from 0 to yield strength. The heating of this bar to higher temperature does not cause further increase of these stresses. Based on these two assumptions there was created an analytical model (Okerblom 1958) to describe the breadth of HAZ and associated distributions of welding residual stresses.

As an example in Figure 8 the analytical model used for $\mathrm{T}$ welded connection is presented. By using equation (1) the HAZ area can be calculated. In this area it has been assumed that the tensile residual stresses reach the yield strength that stay in consistence with experimental measurement presented in Pasternak et al. (2011) and second assumption of models showed in Figure $7 \mathrm{~b}$. Outside this zone, the compressive stresses appear which should be calculated from equilibrium condition. The Eqn (1) can be used also for other cross-sections, for

a)

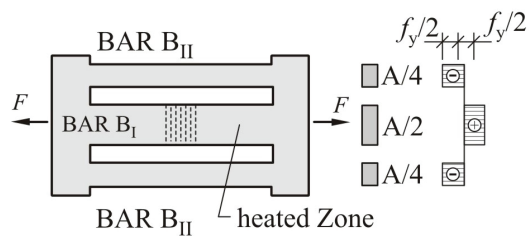

b)

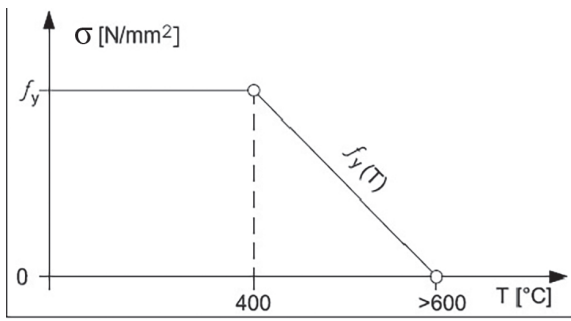

Fig. 7. a) 3-Bar model; b) simplified temperature (T) - yield strength $\left(f_{y}\right)$ relationship 


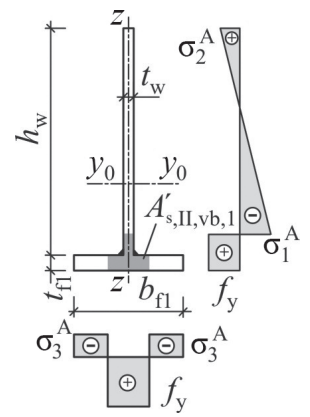

Fig. 8. Analytical calculation of area of HAZ and residual stresses for T profile

example I profile (see Fig. 9), which is a big advantage of this model. Moreover this equation takes into consideration many other parameters like: welding technique, yield strength and stiffness of cross-section:

$$
A_{s . I I . v b}^{\prime}=\frac{7.26 \cdot q_{1}}{f_{y} \cdot\left(\frac{A_{a} \cdot z^{2}}{J_{o}}+\frac{A_{c}}{A_{c}-A_{a}}\right)} \cdot[2+(m-2) \cdot i],
$$

where: $f_{y}$ - yield strength; $q_{1}$ - linear warm energy of welding; $A_{a}$ - area of HAZ of the girder; $A_{c}-$ crosssection area of the girder; $z$ - distance between centres of gravities of HAZ and cross-section; $J_{o}-$ moment of inertia of the girder cross-section; $m, i$ - parameters connected with welding procedure $(m=2.0, i=0.94)$.

\section{Example of use of Okerblom's model on typical I welded cross-section}

The calculation method of longitudinal residual stresses, with use of above described analytical model, will be presented on the example of typical I welded cross-section (see Fig. 12). During the welding of I section, two steps should be analysed (see Fig. 9) i.e. the welding of one flange to the web (see Fig. 11) and the second step is welding of the second flange (see Fig. 11). In both steps welding stresses arise which should be added together in

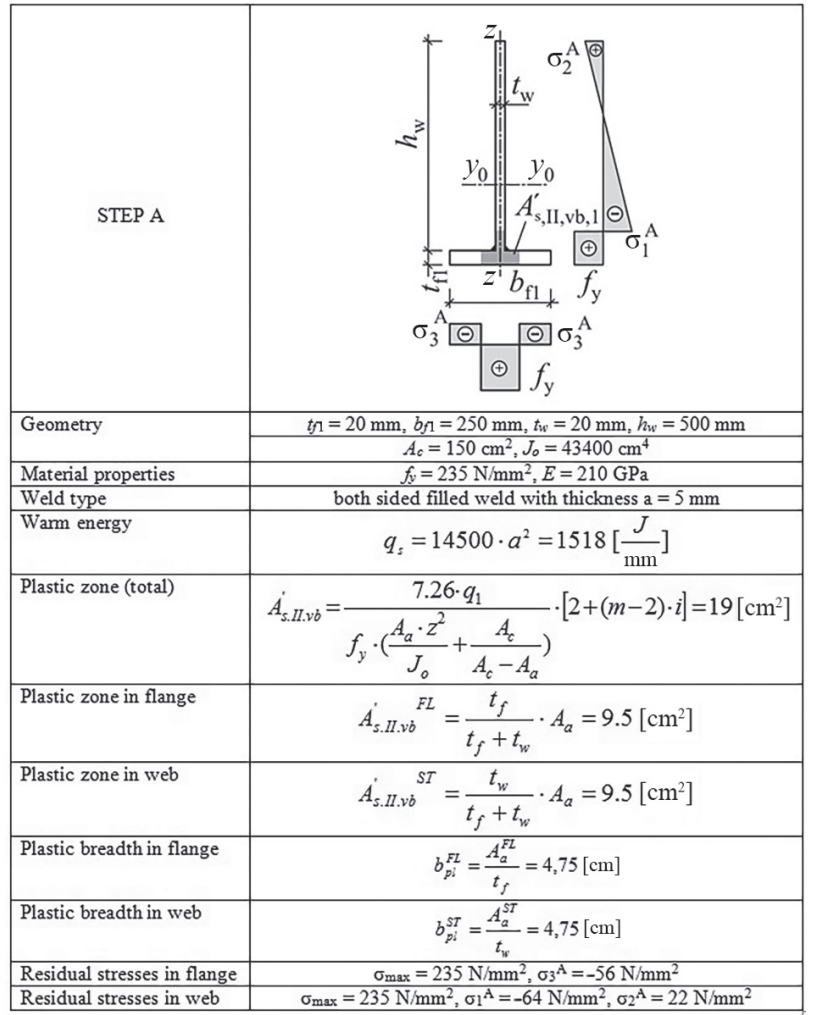

Fig. 10. Procedure of calculation of residual stresses for I cross-section in step A

third step (see Fig. 12). In Figures 10, 11 and 12 detailed results of calculations for every of above mentioned steps were presented. These results were later compared with results shown in Section 6 model based on experiments (ECCS 1983; Johansson et al. 2007; Petersen 1993) (see Table 1). This model can be easily used in structural calculations of many different cross-sections. The structure of equations used to calculate the areas and breadths of HAZ allows taking into consideration many important parameters like welding parameters, weld thickness, procedure of welding, steel grade and profile type.
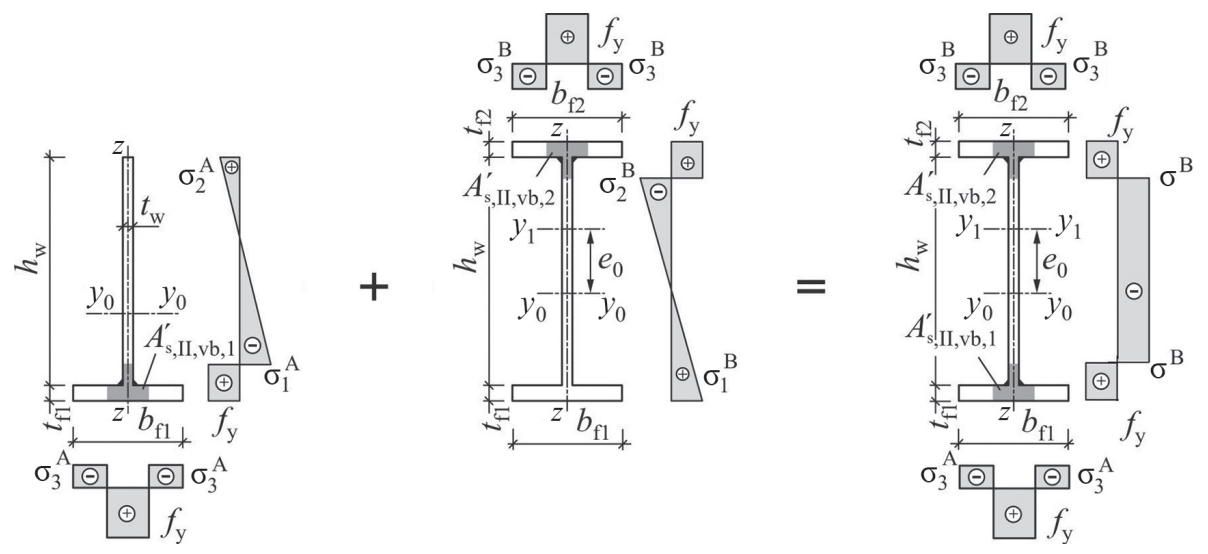

Fig. 9. Procedure of calculation of residual stresses for I cross-section 
Table 1. Comparison of analytical and experimental models

\begin{tabular}{lcccc}
\hline \multicolumn{1}{c}{ Model } & ECCS (1983) & Johansson et al. (2007) & Petersen (1993) & Okerblom (1958) \\
\hline Warm energy [J/mm] & - & - & - & 1518 \\
\hline Area of plastic zone in flange $\left[\mathrm{cm}^{2}\right]$ (average) & $15-25(20)$ & $12-24(18)$ & 20 & 19 \\
\hline Area of plastic zone in web $\left[\mathrm{cm}^{2}\right]$ (average) & $7.5-12.5(10)$ & $6-12(9)$ & 10 & 9.5 \\
\hline Breadth of plastic zone in flange [mm] (average) & $7.5-12.5(10)$ & $6-12(9)$ & 10 & 47.5 \\
\hline Breadth of plastic zone in web [mm] (average) & $37.5-62.5(50)$ & $30-60(40)$ & 230 & 47.5 \\
\hline Tension stresses in flange $\left[\mathrm{N} / \mathrm{mm}^{2}\right]$ & 235 & -57 & -60 & 235 \\
\hline Compression stresses in flange $\left[\mathrm{N} / \mathrm{mm}^{2}\right]$ & -60 & 235 & 235 & -56 \\
\hline Tension stresses in web $\left[\mathrm{N} / \mathrm{mm}^{2}\right]$ & 235 & -76 & -60 & 235 \\
\hline Compression stresses in web $\left[\mathrm{N} / \mathrm{mm}^{2}\right]$ & -60 & & -60
\end{tabular}

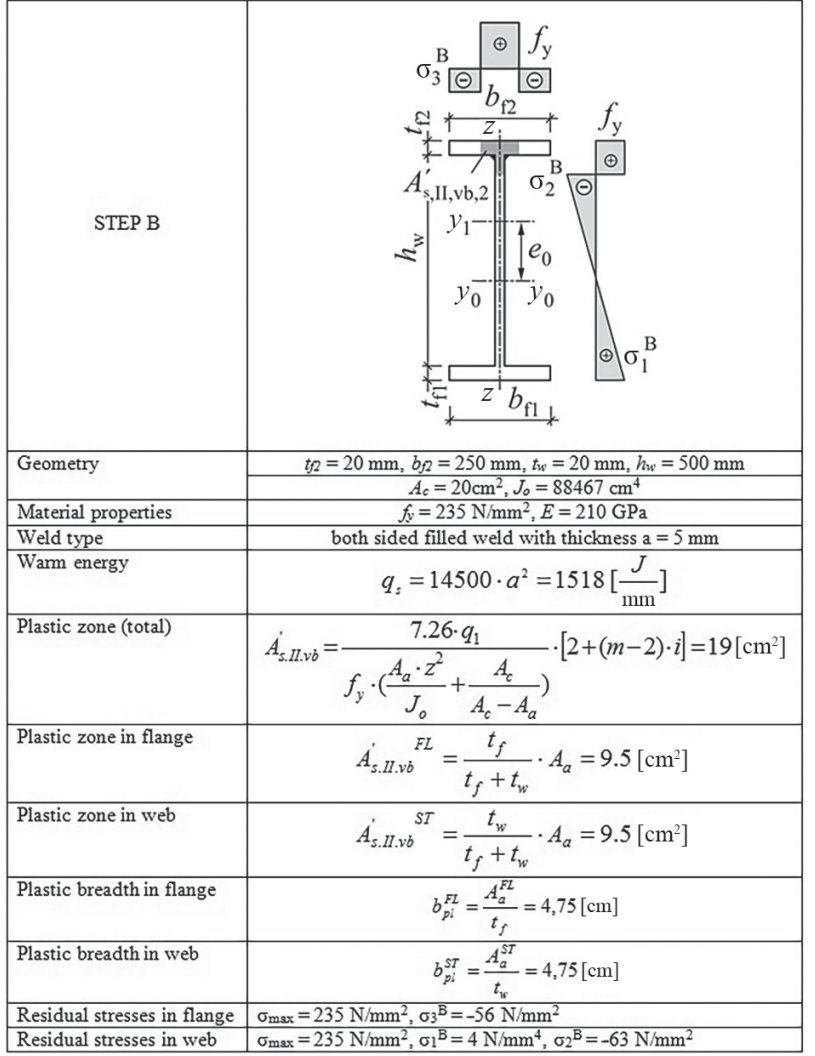

Fig. 11. Procedure of calculation of residual stresses for I cross-section in step B

\section{Numerical calculation}

In this chapter the implementation of the results of the analytical model into numerical simulation will be presented. Five compressed columns (C1-C5), with geometrical and material properties showed on Figure 13, they were numerically tested with integration of longitudinal welding stresses, calculated with use of analytical model presented in Section 4.2. The calculated welding stress distributions were implemented into the model as an initial stress state. In the close vicinity of filled weld i.e. in the HAZ zone, these stresses were assumed as the tensile stresses with the magnitude of yield strength, while outside this zone as the compressive stresses with magni-

\begin{tabular}{|l|l|}
\hline \multirow{5}{*}{ STEP C } & \\
\hline Geometry & \\
\hline Material properties & $A_{\mathrm{v}}=235 \mathrm{~N} / \mathrm{mm}^{2}, E=210 \mathrm{GPa}$ \\
\hline Weld type & both sided filled weld with thickness a $=5 \mathrm{~mm}$ \\
\hline Residual stresses in flange & $\sigma_{\max }=235 \mathrm{~N} / \mathrm{mm}^{2}, \sigma^{\mathrm{B}}=-56 \mathrm{~N} / \mathrm{mm}^{2}$ \\
\hline Residual stresses in web & $\sigma_{\max }=235 \mathrm{~N} / \mathrm{mm}^{2}, \sigma^{\mathrm{A}}=-60 \mathrm{~N} / \mathrm{mm}^{2}, \sigma^{\mathrm{B}}=-60 \mathrm{~N} / \mathrm{mm}^{2}$ \\
\hline
\end{tabular}

Fig. 12. Procedure of calculation of residual stresses for I cross-section in step C

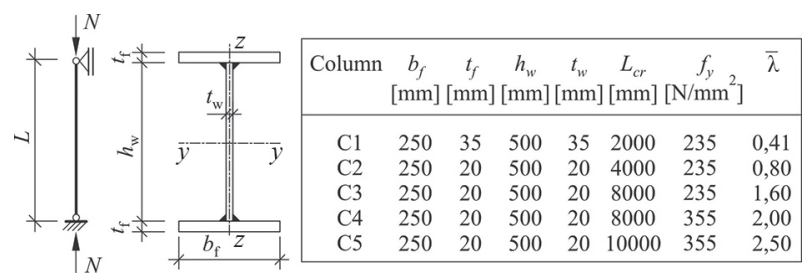

Fig. 13. Geometrical and material properties of the analysed compressed columns

tude resulting from equilibrium condition (see Fig. 14). The numerical model of columns was created using the general purpose program Abaqus 6.8.2 (Hibbit \& Karlsson \& Sorensen, Inc. 2001). Every model was created as a deformable, $3 \mathrm{D}$, shell finite element with assigned homogeneous section with thickness value and material properties. In the numerical calculation both geometrical and structural imperfections were taken into account. The geometrical imperfections were considered as a first eigenmodes resulting from buckling analysis. Moreover the following assumptions were also taken into account: bifurcational elastic analysis (LBA) for determination of 


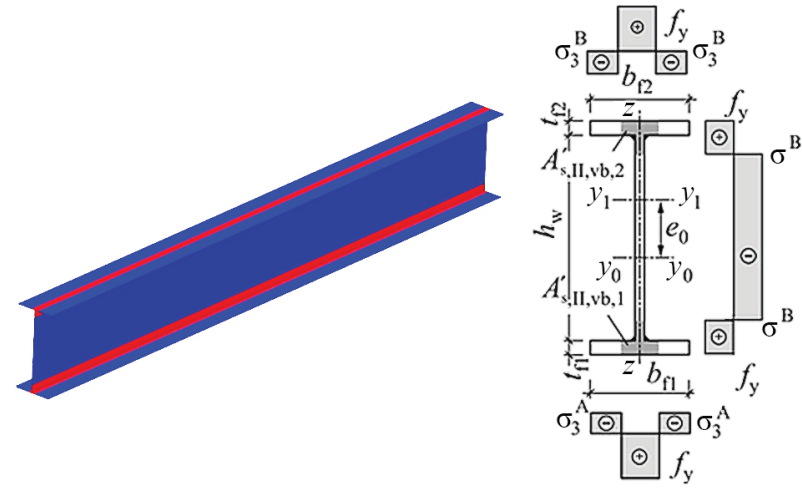

Fig. 14. Longitudinal welding stresses used in numerical simulations

the first eigenform of the column; geometrically and materially non-linear imperfections analysis (GMNIA) for determination of ultimate capacity of all models; shell finite elements (S4R5) were used to discretize models; loads and boundary conditions were defined in appropriate coordinate systems; convergence criteria - displacement. In every case two analyses were carried out: (1) model with only geometrical imperfections with amplitude equal to $\mathrm{L}_{\mathrm{cr}} / 150$ (EN 1993-1-5 2006) and (2) model with geometrical imperfections with amplitude equal to $\mathrm{L}_{\mathrm{cr}} / 1000$ and structural imperfections (residual stresses).

The first analysis represents the described in C.5 (2) of Annex C of EN 1993-1-5 (2006) simplified calculation method while second the described in C.5 (1) more refined analysis. All results were compared with the European buckling curves i.e. $\chi$ - procedure (see Fig. 15).

The nonlinear analysis with combination of structural and geometrical imperfections gives very good results in comparison with buckling curve "c". In analysis only geometrical equivalent imperfections leads to huge differences in reduction factors $\chi$. These results show that the structural imperfections, calculated with use of Okerblom's model (Okerblom 1958), are sufficient enough to numerically describe the real behaviour of compressed members. These results can also suggest the use of the analytical model in calculation of welding residual stresses of any $\mathrm{T}$ or I cross-sections.

As mentioned previously, the welding residual stresses can reach the magnitude of the yield strength only in case of structural steels. For the high strength steels there was proved in Beg and Hladnik (1994) that this stresses are lower than the yield strength and the difference can be even $50 \%$. This problem was investigated in example of compression I column made from steel S460 (see Fig. 16) for which five analysis were carried out (see Table 2). The analyses A1, A2, A3 and A4 include combinations of the structural imperfection, calculated with use of the analytical model, and the geometrical imperfections in form of initial deflection of column $w_{o}$.

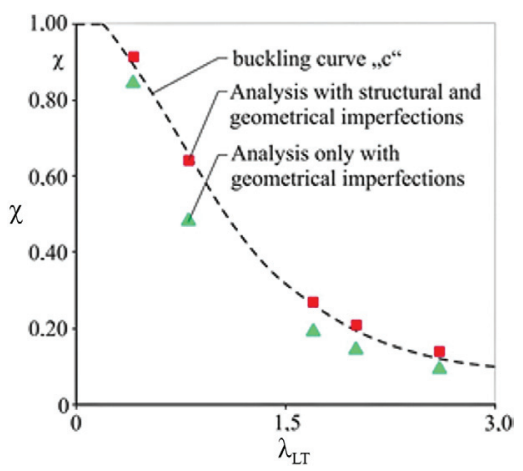

Fig. 15. Comparison of numerical results with buckling curve "c"

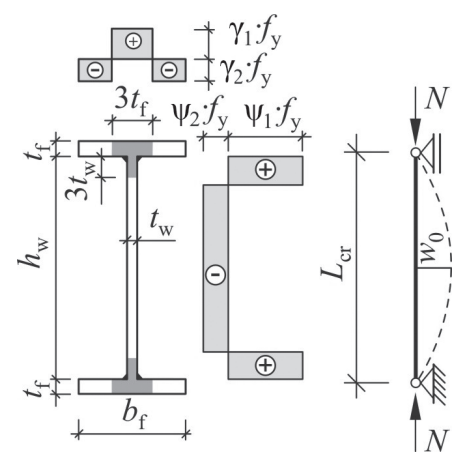

Fig. 16. Geometry and imperfections of the analysed column

Table 2. Geometrical and structural imperfection of the analysed column

\begin{tabular}{|c|c|c|c|c|c|c|c|c|c|c|}
\hline \multicolumn{6}{|c|}{ Geometrical and material properties } & \multirow{3}{*}{$\begin{array}{c}\begin{array}{c}\text { Geometrical } \\
\text { imperfection }\end{array} \\
w_{o}[\mathrm{~mm}]\end{array}$} & \multicolumn{4}{|c|}{ Structural imperfection } \\
\hline \multirow{2}{*}{$\frac{b_{f}[\mathrm{~mm}]}{250}$} & \multirow{2}{*}{$\begin{array}{c}t_{f}[\mathrm{~mm}] \\
20\end{array}$} & \multirow{2}{*}{$\begin{array}{c}h_{w}[\mathrm{~mm}] \\
500\end{array}$} & \multirow{2}{*}{$\frac{t_{w}[\mathrm{~mm}]}{20}$} & \multirow{2}{*}{$\begin{array}{c}L_{c r}[\mathrm{~mm}] \\
4000\end{array}$} & \multirow{2}{*}{$\frac{f_{y}\left[\mathrm{~N} / \mathrm{mm}^{2}\right]}{460}$} & & \multicolumn{2}{|c|}{ Flange } & \multicolumn{2}{|c|}{ Web } \\
\hline & & & & & & & $\begin{array}{c}\gamma_{1} f_{y} \\
{\left[\mathrm{~N} / \mathrm{mm}^{2}\right]}\end{array}$ & $\begin{array}{c}\gamma_{2} f_{y} \\
{\left[\mathrm{~N} / \mathrm{mm}^{2}\right]}\end{array}$ & $\begin{array}{c}\psi_{1} f_{y} \\
{\left[\mathrm{~N} / \mathrm{mm}^{2}\right]}\end{array}$ & $\begin{array}{c}\psi_{2} f_{y} \\
{\left[\mathrm{~N} / \mathrm{mm}^{2}\right]}\end{array}$ \\
\hline \multicolumn{6}{|c|}{$\mathrm{A} 1-50 \% \mathrm{HAZ}+L_{c r} / 1000$} & 4 & 230 & -73 & 230 & -32 \\
\hline \multicolumn{6}{|c|}{$\mathrm{A} 2-100 \% \mathrm{HAZ}+L_{c r} / 1000$} & 4 & 460 & -145 & 460 & -63 \\
\hline \multicolumn{6}{|c|}{$\mathrm{A} 3-50 \% \mathrm{HAZ}+L_{c r} / 500$} & 8 & 230 & -72 & 230 & -31 \\
\hline \multicolumn{6}{|c|}{$\mathrm{A} 4-100 \% \mathrm{HAZ}+L_{c r} / 500$} & 8 & 460 & -145 & 460 & -63 \\
\hline \multicolumn{6}{|c|}{$\mathrm{A} 5-L_{c r} / 150$} & 27 & 0 & 0 & 0 & 0 \\
\hline
\end{tabular}


The values of structural imperfection were formulated in dependence of the yield strength as similar to the models based on experiments. The values of $\gamma_{i}$ and $\psi_{i}$ are the scaling factors used in connection with yield strength to describe maximal and minimal residual stresses in flange and web respectively. These analyses show the influence of the value of welding residual stresses on the reduction factor $\chi$. The fifth analysis A5 contains only the geometrical equivalent imperfections equal to $L_{c r} / 150$. Figure 17 shows results of numerical simulations, huge influence of the value of longitudinal welding stresses on the capacity of welded column could be observed. The lower the value of welding stresses is the higher carrying capacity the column possesses. It can be easily noticed that in case of analysis A1 the reduction factor could be better estimated with use of curve "a". To prove this, more experimental research should be carried out. In calculations only equivalent geometrical imperfections leads to very low capacity, significantly under the curve "c". The difference in reduction factors between analyses A1 and A5 reaches about $47 \%$, between analysis A1 and curve c" abut $18 \%$ and between analysis A5 and curve "c" about $24 \%$. These differences suggest that in case of members made from high strength steels the nowadays design conditions are very conservative.

Apart from magnitude of residual stresses the other factor which significantly influences the capacity of welded structural elements is the breadth of HAZ. This influence will be illustrated with the help of the above mentioned compression column (see Fig. 16). The originally calculated size of breadths of HAZ (60 mm in flange and in web) was three times decreased to values of $75 \%$ $(45 \mathrm{~mm}), 50 \%$ (30 mm) and 25\% (15 mm). The calculations were carried out for two steel grades i.e. S235 and S460. In all calculation the combination of structural $(100 \% \mathrm{HAZ})$ and geometrical $\left(L_{c r} / 1000\right)$ imperfections were used. All results were compared with buckling curve "c" and equivalent geometrical imperfection method (see Figs 18 and 19). The numerical analysis confirmed that the bigger the size of breadth of HAZ zone is the lower the capacity of structural member gets. This regularity is independent on the steel grade. This parametric study suggests that the difference of calculation of sizes

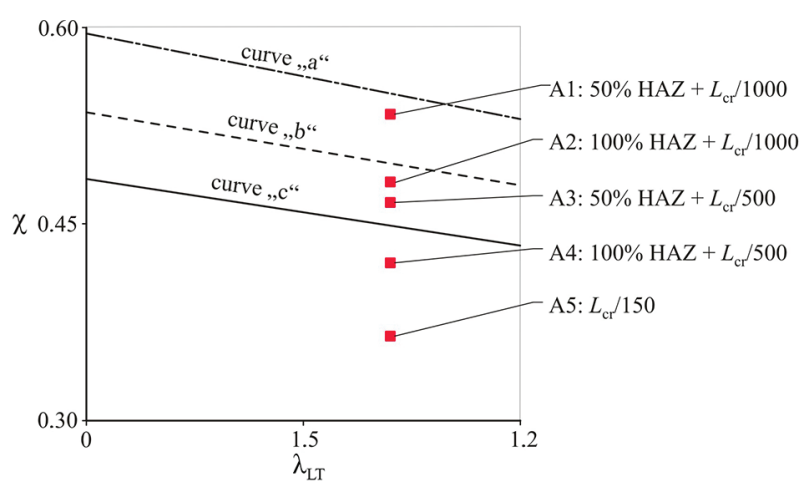

Fig. 17. Comparison of numerical results with buckling curves

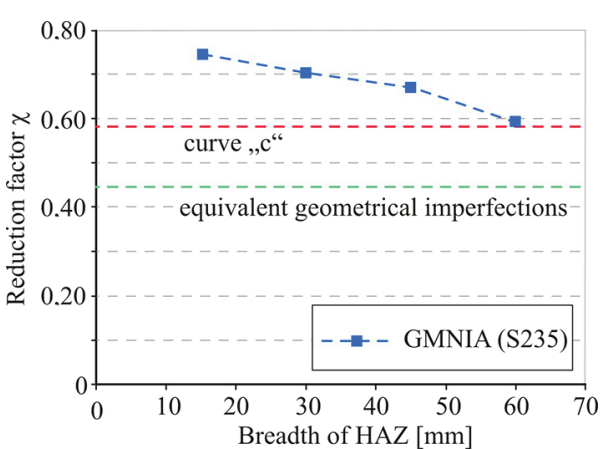

Fig. 18. Comparison of numerical results with buckling curves for steel S235

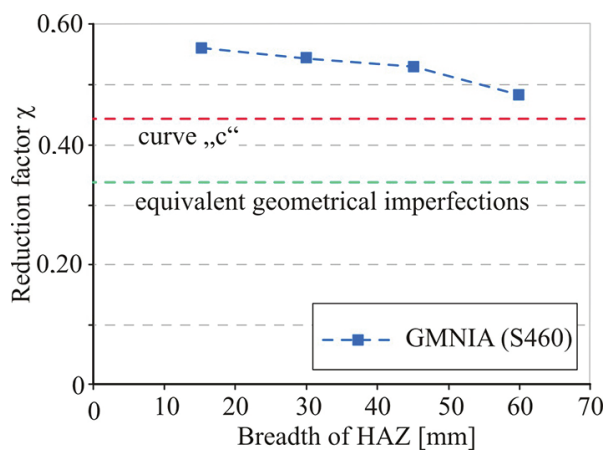

Fig. 19. Comparison of numerical results with buckling curves for steel S460

of breadths of HAZ, proposed by models based on experiments (Johansson et al. 2007; Petersen 1993; Okerblom 1958) and shown in Figure 6, can lead to significantly different estimations of the capacity of welded member. Also in this case there was proved that if using only equivalent geometrical imperfections in calculation leads to very low capacity, significantly under the curve "c".

\section{Conclusions}

The carried out analysis resulted in the following conclusions:

- The actual state of art in welding shows that during the welding three types of imperfections can arise, i.e. structural, geometrical and assembly; the knowledge of the welding process and the ease of identification of welding deformations in welded elements allow to reduce the geometrical imperfections to a minimum level.

- The structural imperfections should be taken into consideration during the structural calculations of stability sensible members; to determine the capacity of such members 3 methods can be used: (1) $\chi$ - procedure (European buckling curves); (2) equivalent geometrical imperfection procedure and the most accurate; (3) yield zone theory (GMNIA).

- The implementation of structural imperfections in FE calculations is difficult because of the absence of information about theirs values and distributions.

- The models based on experiments (measurements of residual stresses) are valid only for particular 
cross-sections and do not include information about the main parameters influencing stress distributions, i.e.: welding parameters, weld thickness, procedure of welding, steel grade and profile type.

- A better description of welding stress distribution can deliver by Okerblom's model, which is based on two assumptions, i.e. the 3-bar model and the simplified yield strength - temperature relationship, includes all necessary information needed for description of welding stress distribution and can be used for every type of cross-section.

- The results obtained according to this model stay in very good adequacy in comparison with experimental ones. The results of nonlinear numerical analysis for T or I cross-sections show that the structural imperfections, are sufficient adequate to describe numerically the real behaviour of members under compression.

- The carried out numerical analysis confirms the following regularities, i.e.: (1) the lower the value of welding stresses is the higher carrying capacity the column possesses; (2) that the bigger the size of breadth of HAZ is the lower the capacity of structural element gets; and (3) that using only equivalent geometrical imperfections in calculation leads to very low capacity, significantly under the buckling curves.

- It was also proved that in case of members made from high strength steels the nowadays design conditions are very conservative.

- The difference of sizes of HAZ breadths of T or I cross-sections, proposed by simplified models showed on Figure 6, can lead to significantly different estimations of capacity of welded elements.

- The Okerblom's model can be used for structural steels and welding techniques like MAG, MIG or TIG; in case of high strength steels and welding techniques like laser (LBW) or plasma (PAW) welding this model requires some modifications.

\section{References}

Beg, D.; Hladnik, L. 1994. Eigenspannungen bei geschweißten I-Profilen aus hochfesten Stählen, Stahlbau 63(5): 134139 (in German).

ECCS. 1983. Ultimate limit state calculation of sway frames with rigid joints. Publication No 33. Brussels: ECCS General Secretariat. $20 \mathrm{p}$.
EN 1090-2:2008 Execution of steel structures and aluminium structures, Part 2: Technical requirements for the execution of steel structures. European Committee for Standardization (CEN), Brussels, 2008. 112 p.

EN 1993-1-1 Design of steel structures, Part-1-1: General rules and rules for building. European Committee for Standardization (CEN), 2006. 93 p.

EN 1993-1-5 Design of steel structures, Part-1-5: Plated structural elements. European Committee for Standardization (CEN), Brussels, 2006. 55 p.

Hibbit \& Karlsson \& Sorensen, Inc. 2001. ABAQUS theory and user's manual, Version 6.2. Pawtucket, Rhode Island. $27 \mathrm{p}$.

Johansson, B.; Maquoi, R.; Sedlacek, G.; Müller, C.; Beg, D. 2007. Commentary and worked examples to EN 1993-1-5 "Plated structural elements". $1^{\text {st }}$ ed. Joint report prepared under the JRC - ECCS cooperation agreement for the evolution of Eurocode 3 (programme of CEN/TC 250). Luxembourg: Office for Official Publications of the European Communities. 242 p.

Lee, C.-H.; Chang, K.-H. 2007. Numerical analysis of residual stresses in welds of similar or dissimilar steel weldments under superimposed tensile loads, Computational Materials Science 40(4): 548-556. http://dx.doi.org/10.1016/j.commatsci.2007.02.005

Okerblom, N. O. 1958. The calculations of deformations of welded metal structures. London: Her Majesty's Stationery Office. $234 \mathrm{p}$.

Pasquale, P. 2001. Numerische Simulation schweißtechnischer Fertigungsschritte: Dissertation. Karlsruhe Institute of Technology, Karlsruhe, Germany (in German).

Petersen, C. 1993. Stahlbau - Grundlagen der Berechnung und baulichen Ausbildung von Stahlbauten. 3. überarbeitete und erweiterte Auflage. Braunschweig/Wiesbaden: Vieweg. 1420 s. (in German).

Pasternak, H.; Bachmann, V.; Kubieniec, G.; Dilger, K.; Vogt, M.; Workowski, M.; Urner, M. 2011. Einsatz der Schweißsimulation zur Verbesserung der Tragfähigkeitsberechnungen komplexer Stahlleichtbaustrukturen, Bauingenieur 86(11): 493-500 (in German).

Radaj, D. 1998. Simulation von Temperaturfeld, Eigenspannungen und Verzug beim Schweißen. DSV-Berichte Band 214. Düsseldorf: DVS-Verlag GmbH (in German).

Rykaluk, K. 1981. Residual welding stresses in chosen ultimate bearing capacity. Scientific Papers of the Institute of Building Engineering of Wroclaw Technical University, Monograph No. 11. Wroclaw: Institute of Building Engineering of Wroclaw Technical University (in Polish).

Schulz, G. 1968. Die Traglastberechnung von planmäßig mittig belasteten Druckstäben aus Baustahl unter Berücksichtigung von geometrischen und strukturellen Imperfektionen: Dissertation. Graz, Austria (in German).

Wolf, C. 2006. Tragfähigkeit von Stäben aus Baustahl - Nichtlineares Tragverhalten, Stabilität, Nachweisverfahren: Dissertation. der Ruhr-Universität Bochum, Bochum, Germany (in German).

Hartmut PASTERNAK. Prof. Dr-Ing. Habil. In Brandenburg University of Technology is involved in teaching, research and design of steel structures for more than 25 years. He is member in several National and International Committees (e.g. full member of the ECCS Technical Committee 8 "Structural Stability", member of German subcommittee DASt-Ri015 "Girders with thin webs", member of COST C25 action "Sustainability of Constructions", member of the working group Eurocode 3 "Crane supporting structures"). He has participated in numerous research projects (e.g. on thin-walled members, welding stresses and adhesive bonded joints ). Under his supervision 9 PhD's were completed. He has more than 100 publications in Journals and at Conferences and is co-author of books in German (4) and English (1) on steel structures. Moreover he is the editor of the journal "Bauingenieur" for steel structures.

Gabriel KUBIENIEC. Dr-Ing. Is a scientific assistant at the Brandenburg University of Technology since 2009. His research interests include the behaviour of thin-walled steel structures and welding stresses. He has 14 publications in journals and at conferences. 